\title{
International Journal of Waste
}

\section{Conversion of Biomass and Waste to Value-add Products: Challenges and Opportunities}

Sherif Elshokary ${ }^{1^{*}}$, Sherif Faraga ${ }^{2,3}$, Osayed Abuelyazeed ${ }^{1}$, Bitu Hurisso $^{4}$ and Mostafa Ismail ${ }^{1}$

${ }^{1}$ El-Mattaria, Helwan University, Cairo, Egypt

${ }^{2}$ Ecole Polytechnique Montreal, P.O. Box 6079, Station Centre-ville, Montreal, QC, Canada H3C 3 A7

${ }^{3}$ RMTech for Environmental Solutions Inc., Canada

${ }^{4}$ Chemistry Department, Atlantic Centre for Green Chemistry, Saint Mary's University, Halifax, Nova Scotia Canada B3H 3 C3

*Corresponding author: Sherif Elshokary, Faculty of Engineering at El-Mattaria, Helwan University, Cairo, Egypt, Tel: +201020002590; E-mail:

sherifelshokary@gmail.com

Received date: October 23, 2018; Accepted date: November 08, 2018; Published date: November 15, 2018

Copyright: (c) 2018 Elshokary S, et al. This is an open access article distributed under the terms of the Creative Commons Attribution License, which permits unrestricted use, distribution and reproduction in any medium, provided the original author and source are credited.

\section{Retraction Note:}

The article entitled "Conversion of Biomass and Waste to Value-add Products: Challenges and Opportunities" has been accepted for publication in the International Journal of Waste Resources considering the statements provided in the article as personal opinion of the author which was found not having any conflict or biasness towards anything. As the article was a perspective one, information provided by the author was considered as an opinion to be expressed through publication.

Publisher took decision to make the article online solely based on the reviewers suggestion which considered the article not but a personal opinion of the author. However, it is found that the author have some personal concerns and issues, therefore, being retracted from the journal. 